\title{
Research on Influence of Energy Internet on Organizational Form of Power Grid Enterprise
}

\author{
Hualei Zhang ${ }^{1 *}$, Jian Zhao ${ }^{1}$

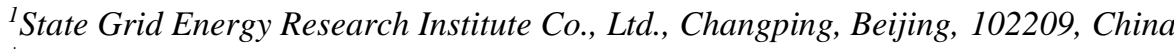 \\ *Corresponding author. Email: 18093905708@163.com
}

\begin{abstract}
The Energy Internet is deeply integrated with energy systems and emerging technologies such as the "Cloud Computing, Big Data Technologies, the Internet of Things, Mobile Internet, Artificial Intelligence", which accelerates the transformation of the traditional energy system driven by fossil energy into a new energy system that is clean, lowcarbon, efficient and safe. This also brings challenges to the traditional organizational structure of power grid enterprise By analyzing the characteristics of the Energy Internet, the general law of evolution of the enterprise form, and the developing history of typical Internet enterprises, this paper proposes the direction of business evolution of the Energy Internet, and the direction of the organizational structure optimization for the power grid enterprise, so as to provide some support for the transformation of enterprise's organizational form in the future.
\end{abstract}

\section{Keywords: Energy Internet, organizational form, power grid enterprises, organizational structure}

\section{INTRODUCTION}

In recent years, the energy world is undergoing a transition period towards a new energy world, and China's energy industry is facing significant opportunities and challenges. General Secretary Xi Jinping put forward the major energy strategic thought of "Four revolutions and one Cooperation" at the sixth Meeting of the Central Leading Group for Financial and Economic Affairs on June 13, 2014, which pointed out the direction of China's energy development in the new era. The Internet can effectively solve the problem of information asymmetry in the current economy, optimize the allocation of resources and reduce transaction costs. Under the development trend of the Energy Internet, the digital and Internet transformation of enterprises has gradually become an important direction of transformation[1].

At present, China's electric power system reform is deepening, and the transformation of energy system is in a critical period[2]. As the core enterprise of energy enterprises, power grid enterprise are in the major strategic period of power reform and energy reform, facing two choices. One is to passively adapt to the development of energy Internet, and influence the management mode of enterprises through the operation mechanism of power market. The second option is to optimize and adjust the organizational form with the help of energy Internet technology and platform, so as to realize the establishment of innovation platform and the innovation of organizational management mode[3-4].

\section{CHARACTERISTICS OF ENERGY INTERNET}

\subsection{Multi Concept}

The energy Internet is the introduction of the Internet on the basis of the traditional energy network, which contains the concepts of openness, interconnection and confrontation[5].

Open energy is the core concept of the Internet, mainly reflected in the open system interconnection, all kinds of equipment and multi-type energy open peer, all kinds of participants and end user access to the open participation, open energy market and trading platform, open energy innovation entrepreneurship environment, open the energy of the Internet ecosystem, and open data and standard and so on.

Interconnection is an important form of openness. It can provide a platform for energy sharing and trading, and connect supply and demand. It is the basis for creating value in the energy Internet. Interconnection includes the interconnection of multiple energy forms, multiple energy systems, multiple heterogeneous devices, and various participants. 
Reciprocity is one of the forms of the energy Internet. The energy Internet needs to break monopoly and decentralize. Different participants are in an equal position and conduct reciprocal transactions on this basis. Energy production and consumption are also equal. It is no longer a one-way production tracking consumption pattern, but a two-way or even multilateral one.

\subsection{Multi Technology}

The construction of the energy Internet needs to be supported by breakthroughs in key technologies such as energy production, transformation, transmission, storage and access[6]. In terms of energy production, distributed photovoltaic, wind power and other new energy technologies will realize low-carbon and clean energy Internet. In terms of energy conversion, the free and efficient conversion of energy, such as the cold, heat and electricity co-production units and the conversion of electricity to hydrogen, will be realized to promote the reliability and flexibility of the energy system. In terms of energy transmission, wireless charging technology and HVDC will realize the convenience of energy transmission. In terms of energy storage, efficient batteries and heat pumps will realize the low-cost and efficient storage of various forms of energy, breaking the real-time balance constraint of energy, especially electricity production and consumption. In terms of energy access, multi-stage DC technology and solid state transformer will realize the free access and plug and play of power generation and electric equipment[7].

Specifically, the multi technology features of energy Internet include new energy power generation technology, large capacity long-distance transmission technology, advanced energy storage technology[8], advanced information technology, demand response technology[9], micro energy network technology and standardization technology.

\subsection{Multi Service}

Energy Internet means multi business collaborative support. Both traditional business and emerging business can be expanded with the development of energy Internet technology. Meanwhile, multi type business integration also forms the business architecture of energy Internet.
Combined with the construction process of energy Internet, it is necessary to integrate the concepts of openness, interconnection, user-centered, distributed, sharing and peer-to-peer; it is necessary to integrate the marketing system, Internet of vehicles, photovoltaic cloud network and State Grid e-commerce platform into the shared operation platform, and create an energy distribution platform, comprehensive service platform and new business new format and new mode development platform, so as to give full play to the company Platform value advantage; it is necessary to apply many advanced technologies in energy production, transformation, transmission, storage and access to build the physical layer architecture of energy Internet and realize the function of energy Internet connection; with the help of the energy Internet, by optimizing the traditional business and developing the new business, the power grid company can realize the new situation of multi-business coordinated development.

Power Grid Corp can use cloud technology and smart chain technology to integrate grid operation information and user energy information, to achieve integration of basic resources, platform support and application services, and fully support the business application of the Internet plus integrated energy operation service platform, and create an energy and Internet industry ecosystem.

\section{ANALYSIS ON THE DIRECTION OF ENTERPRISE ORGANIZATIONAL CHANGE UNDER THE ENERGY INTERNET}

\subsection{Evolution Law of Enterprise Organization Form}

Organizational form refers to an invisible and relatively stable enterprise framework formed by vertical hierarchical relationship, horizontal division of labor and cooperation relationship and horizontal and vertical communication relationship in an organization. With the development of industrial revolution and the change of enterprise value concept, the form of enterprise organization gradually experienced the form of shareholder value, elite value, customer value and stakeholder value[10]. 


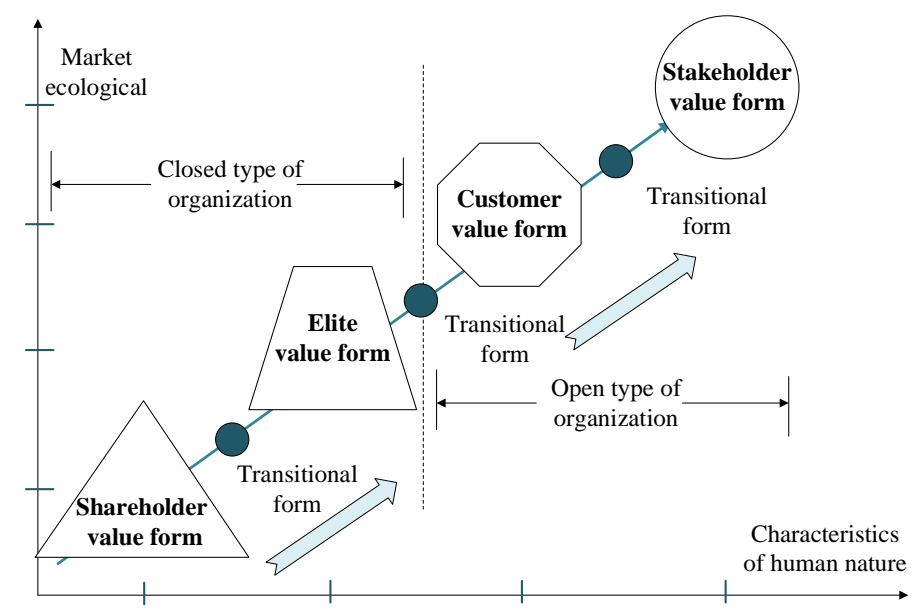

Figure 1 Evolution law of enterprise form

It can be seen from Figure 1 that the shareholder value form and the elite value form mainly focus on the upstream interests of the industrial chain. These enterprises in this form are traditional enterprises, and their organizational structure usually adopts Linear Organization or U-form Organization. The customer value form and the stakeholder value form are more open, focusing on the downstream interests of the industrial chain, and their organizational structures have gradually developed into Process-oriented Organization and Network Organization Structure.

\subsection{Evolution of Typical Enterprise Organization Form}

\subsubsection{The process of organizational change of}

\section{Huawei}

It has been more than 30 years since Huawei was founded and developed. With its keen strategic vision and excellent organizational culture, Huawei has carried out a series of process reengineering and organizational structure changes simultaneously with phased strategic adjustment, and has always maintained its organizational vitality[11]. 1987-1994, in the early stage, Huawei adopted a linear organizational structure, which could quickly and uniformly allocate resources to participate in market competition, and quickly respond to changes in the external environment to match the company's centralized strategic development.

From 1995 to 2003, at this stage, Huawei changed the company's centralization strategy into horizontal integration strategy and expanded its business scope. The original centralized linear organizational structure has brought great pressure on management and coordination for the management. Therefore, Huawei has established a two-dimensional matrix organizational structure combining business unit system with regional department.

From 2004 to 2012, in order to realize the transformation from telecom equipment provider to telecom equipment service provider, Huawei has increased product development efforts and built an organizational structure dominated by product lines.

From 2013 to 2020, during this period, Huawei reintegrated the functional platform of the group, established ICT business organizations and regional organizations, improved the internal governance structure, and achieved clear rights and responsibilities, focused responsibilities, but also decentralized checks and balances the organizational governance structure. The current organizational structure of Huawei is shown in Figure 2. 


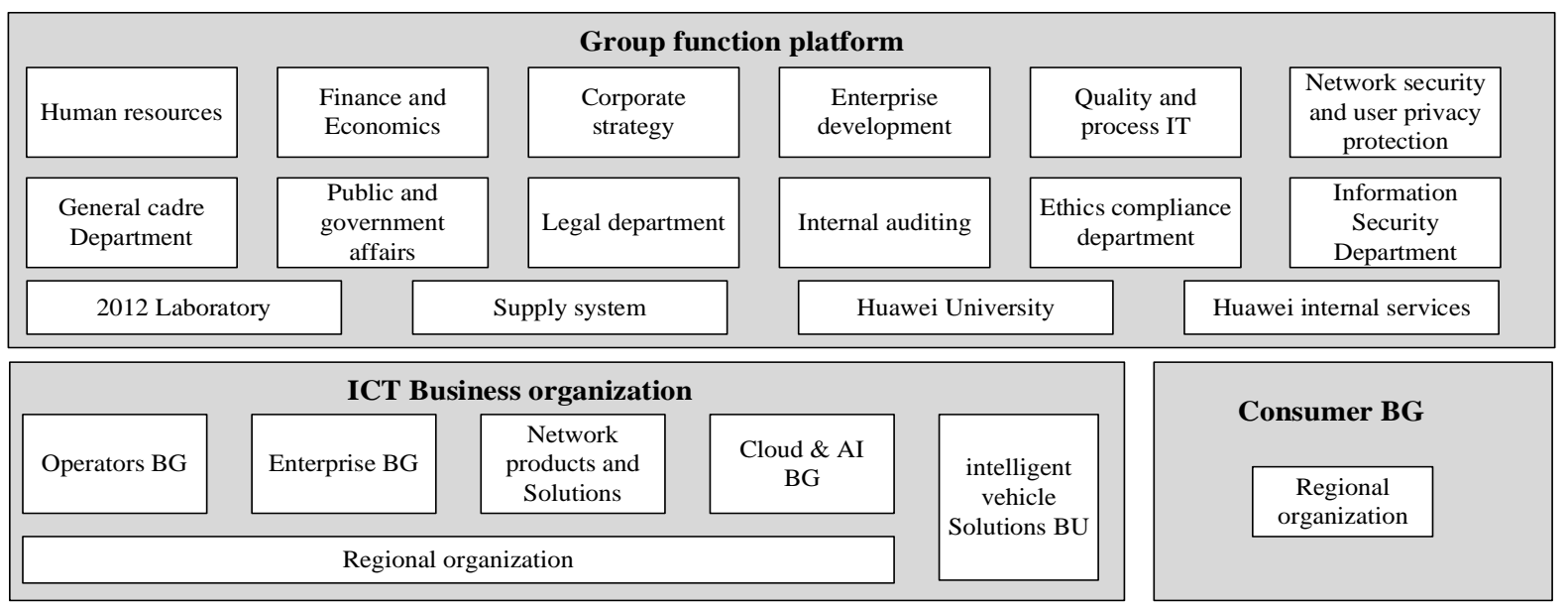

Figure 2 Organizational structure of Huawei

\subsubsection{The process of organizational change of} Tencent

Tencent is one of the most outstanding Internet enterprises in China. After two major organizational structure adjustments and several fine adjustments, Tencent has transformed its functional structure into today's business group form. These adjustments to a certain extent represent the common development trend of Internet enterprises[12].

From 1998 to 2005, functional organizational structure. Tencent\&apos;s main product is QQ. The whole enterprise has the characteristics of single product and small business volume. In this stage, Tencent continuously optimizes QQ products and expands its product market by increasing the exposure rate of QQ.
From 2005 to 2012, business system structure. In this stage, Tencent develops new business areas based on QQ customer group. By giving the product team certain autonomy, Tencent cultivates, develops and tries new products in the way of "small steps and fast running". Thus, Tencent completes the layout of various industries, especially in the "Pan entertainment" industry, and gradually establishes an ecological system with QQ as the core.

From 2012 to 2018, the organizational structure of the business group. Under the organizational structure of business group, Tencent takes departments or product groups as the unit, and a product department can independently set up projects to promote Tencent's core business from simple social contact to six directions of "social, game, Internet media, wireless, e-commerce and search". The current organizational structure of Tencent is shown in Figure 3.

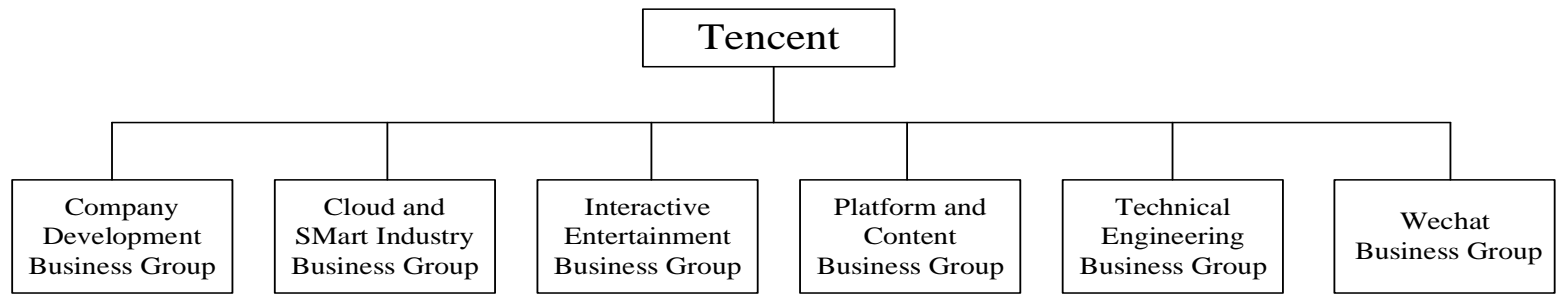

Figure 3 Organizational structure of Tencent business group

\section{ANALYSIS ON BUSINESS EVOLUTION DIRECTION AND ORGANIZATION FORM OF POWER GRID ENTERPRISE ADAPTING TO THE DEVEOPMENT OF ENERGY INTERNET}

\subsection{Business Evolution Direction}

For power grid enterprise, traditional business mainly refers to power transmission and distribution business and power sales business. For the power transmission and distribution business, the company can make use of intelligent robot, UAV and other technologies to create the development scene of energy Internet, strengthen asset lean management and investment economic benefit calculation, reduce business costs and improve unit investment return rate. In terms of electricity sales, power grid companies can integrate users, assets, data, funds, services and other resources to carry out spot market and financial market transactions. In addition, energy big data technology can be used to analyze the characteristics of customer groups and consumption rules, and establish "electricity consumption archives" to provide diversified, personalized and package type tariff services for users.

The new business includes additional value-added services such as integrated energy services, energy 
management contracts, electric vehicles and financial services[13]. Under the energy Internet, integrated energy services can break the institutional mechanism and technical barriers of various industries, realize the joint supply of cold, heat, electricity, gas, hydrogen and other energy, and improve the comprehensive utilization rate and comprehensive efficiency of energy. In addition, it can also contract with the energy users to agree on the target of energy projects, and provide a series of comprehensive services such as energy-saving diagnosis, analysis and calculation, including electricity, gas and water. Electric vehicle business is also the focus of business development under the new situation of energy Internet. Through the construction of intelligent Internet of vehicles platform, the professional management of electric vehicle rental and charging business is realized[14].

\subsection{Analysis of Enterprise Evolution}

With the diversified development of business and the construction of energy Internet, power grid enterprise needs to establish multi module / business group network organization structure to realize the transformation of traditional industrial value chain to Internet operation platform.

Power equipment vertical e-commerce module. Based on the power equipment procurement demand of power grid enterprise, the vertical e-commerce module of power equipment is constructed to attract relevant enterprises in the supply chain to settle in and promote enterprise transactions. With the help of this module, the company can integrate high-quality supplier resources, provide comprehensive procurement services for power materials for all demanders, and carry out supply chain financial business with the help of supply chain data, so as to meet the financing service needs of customers in power and related industries.

User community module. The company has mastered the complete power consumption resources of users. By building user community function modules, the company can provide users with more accurate and focused services, such as one-stop power service, home energy management, smart home, Internet of vehicles, etc. Relying on the application and business hall of "palm power 2019", it can provide a place for users to communicate and strengthen the communication between users. The establishment of user community module can effectively mine the extended demand, speed up the iterative updating of products, and maintain the core users.

Energy trading service module. It can not only provide consulting services for members of the energy market, but also provide consulting services for the trading and demand side of the electricity market. To realize the development of energy trading service providers.

Resource sharing module. As a power supporting service provider, the company creates resource sharing module and establishes service supplier qualification evaluation system, which can save the cost of resource suppliers and the waiting time of demanders, and ensure the quality of power supporting services.

Energy big data module. Through advanced information technology and energy network architecture technology, power grid companies have accumulated a large amount of power data and continuous data sources, and can carry out value-added services such as data asset operation and analysis services to government agencies, financial institutions, residents, transportation industry and other users, so as to realize the development of data value-added service providers

\section{CONCLUSION}

The Energy Internet has brought about more diversified developing potential and business development opportunities to the traditional power grid enterprises centering on the transmission and distribution of electricity. In the transformation of organizational form of traditional power grid enterprises, in addition to the new technology based on the Energy Internet and the application of platforms, it is also necessary to guide the participation of energy users, the support of the government, and the recruitment of new partners, so as to broaden the business model of power grid enterprises, guide the network-oriented evolution of organizational structure and achieve multi-agent win-win situation.

\section{ACKNOWLEDGMENT}

This work was supported by National Natural Science Foundation of China (71573084), the Fundamental Research Funds for the Central Universities (2019QN006), and Research Project on Key Technologies and Strategies Optimization of the Organization and Management of Power Grid Business for Energy Internet Enterprises (1400-201957292A-0-000).

\section{REFERENCES}

[1] X.D. Yu, X.D. Xu, S.Y. Chen, J.Z. Wu, H.J. Jia, Integrated energy system and energy Internet, Transactions of China Electrotechnical Society, vol.31, Beijing, China, 2016, pp. 1-13. DOI: https://10.3969/j.issn.1000-6753.2016.01.001.

[2] H. Sun, Q. Guo, Energy strategy and energy Internet, Journal of Global Energy Interconnection, vol.18, Beijing, China, 2020, pp. 537-538.

[3] X-J. Yi, Discussion on the reform of enterprise organization structure in the internet era, Journal of 
Commercial Economics, vol. 881, Beijing, China, 2020, pp. 107-110.

[4] G. Liu, Strengthening the coordinated development of organization and management of power grid enterprises, China Power Enterprise Management, vol. 535, Beijing, China, 2018, pp. 66-68.

[5] H. Sun, Q. Guo, Z. Pan, Energy Internet: Concept, Architecture and Frontier Outlook, Automation of Electric Power Systems, vol. 39, Beijing, China, 2015, pp.1-8.

[6] Y. Wu, Y. Wu, et al, Digitalization and decentralization driving transactive energy Internet: Key technologies and infrastructures, International Journal of Electrical Power \& Energy Systems, 2021, 126(PA)

[7] X. Li, J. Li, et al, Research on Implementation Methods of Power Grid Technology Supporting Energy Internet Construction, IOP Conference Series: Earth and Environmental Science, Vol. 558, Chapter 4. Energy Resources, Energy Conversion and Energy Conservation, 2020, (5):052013.

[8] G. Wang, Electric energy storage technology under the background of energy Internet, Management \& Technology of SME, Shijiazhuang, Hebei Province, China, vol. 120, 2019, pp. 165-166.

[9] M. Seyed, H. Amin, S. Miadreza, et al, Demand Response and Flexible Management to Improve Microgrids Energy Efficiency with a High Share of Renewable Resources, Sustainable Energy Technologies and Assessments, vol. 42, 2020, pp. DOI: https://doi.org/10.1016/j.seta.2020.100848

[10] S. Yang, Evolution: organizational form management, China Development Press, Beijing, China, 2014, pp. 101-110.

[11] J. Han, Z. Zhu, References of the Operational Mechanism of Huawei's Organizational Structure on State-owned Enterprises, People's Tribune, vol. 34, Beijing, China, 2019, pp. 28-29.

[12] X. Zhang, A Study on the Organizational Characteristics of the Corporate System for Continuous Innovation-A C. Technology and Innovation Management, Xian, Shanxi Province, China, vol. 37, 2016, pp. 242-249. DOI: https://10.14090/j.cnki.jscx.2016.0304.

[13] Q. Sun, J. Li, Y. Yang, et al, Development Strategies of Power Grid Companies Under Energy Internet and Electricity Policy Reforms, Guangdong Electric Power, vol.33, Guangzhou, Guangdong Province, China, 2020, pp. 71-77.
[14] L. Huang, X. Wang, et al, Analysis of Planning Business Impact Based on "Three Types and TwoNetwork Development Strategy”, Qinghai Electric Power, Xining, Qinghai Province, China, vol. 38, 2019, pp. 62-63+72. DOI: https://10.15919/j.cnki.qhep.2019.02.014. 